\title{
PENGARUH DISKON DAN HADIAH TERHADAP PENGGUNAAN KARTU KREDIT (STUDI PADA PEMANDIRING KARTU KREDIT BANK MANDIRI CABANG MATARAM)
}

\author{
BAIQ RENI SARI DEWI \\ Fakultas Teknik UNMAS Denpasar PSDKU Mataram \\ e-mail:baiqrenisaridewi@gmail.com
}

\begin{abstract}
ABSTRAK
Penelitian ini bertujuan untuk mengetahui adanya pengaruh yang signifikan baik secara parsial maupun simultan dan variabel mana yang memiliki pengaruh paling dominan dari diskon dan hadiah terhadap penggunaan kartu kredit Bank Mandiri cabang Mataram.

Jenis penelitian ini adalah penelitian asosiatif, dengan populasi Mandiri kartu kredit Bank Mandiri cabang Mataram. Teknik sampling yang digunakan dalam penelitian ini bersifat accidental sampling dengan jumlah sampel 60 responden. Dengan teknik dan alat pengumpulan data berupa kuesioner, diperoleh skor yang mengacu pada penggunaan skala likert. Untuk mengetahui hasil perhitungan menurut persamaan regresi dilakukan uji statistik yaitu uji $\mathrm{f}$ dan uji t sebagai alat uji hipotesis.

Hasil analisis menunjukkan bahwa 1). Secara parsial pemberian diskon dan hadiah berpengaruh signifikan terhadap penggunaan kartu kredit Bank Mandiri di Kota Mataram. Hal ini dibuktikan dengan nilai probabilitas masing masing variabel yang lebih kecil dari 0,05. 2) Secara simultan pemberian diskon dan hadiah berpengaruh signifikan terhadap penggunaan kartu kredit Bank Mandiri di Kota Mataram. Hal ini dibuktikan dengan probabilitas nilai f yang lebih kecil dari 0,05 .
\end{abstract}

Kata Kunci : diskon dan hadiah terhadap penggunaan kartu kredit

\section{ABSTRACT}

This study aims to find out the significant influence both partially and simultaneously and which variables have the most dominant influence from discounts and prizes on the use of credit cards of Bank Mandiri branch Mataram.

This type of research is associative research, with a population of credit card holders of the Bank Mandiri branch in Mataram. The sampling technique used in this study is accidental sampling with a sample of 60 respondents. With data collection techniques and tools in the form of a questionnaire, a score is obtained which refers to the use of a Likert scale. To find out the results of calculations according to the regression equation, statistical tests are carried out, namely f test and t test as a hypothesis test tool.

The results of the analysis show that both are 1). Partially giving discounts and prizes has a significant effect on the use of Bank Mandiri credit cards in the city of Mataram. This is evidenced by the probability value of each variable smaller than 0.05. 2) Simultaneously giving discounts and gifts has a significant effect on the use of Bank Mandiri credit cards in the city of Mataram. This is evidenced by the probability of a value of $f$ that is smaller than 0.05 .

Keyword : discount, gift, credit card usage

\section{PENDAHULUAN}

\section{Latar Belakang}

Kondisi perubahan yang cukup cepat terjadi saat ini, telah memberikan wawasan baru bagi manajemen untuk menciptakan suatu strategi bisnis yang menunjang dalam menghadapi perubahan dan fleksibael dalam pelaksanaannya. Hal tersebut menjadikan persaingan antar perusahaan khususnya industri perbankan dalam penyediaan jasa keuangan saat ini semakin ketat. Kasmir (2010 :11), mengatakan bahwa Bank adalah 
lembaga keuangan yang kegiatan utamanya adalah menghimpun dana dari masyarakat dan menyalurkannya kembali dana tersebut ke masyarakat serta memberikan jasa bank lainnya. Jasa adalah setiap kegiatan atau manfaat yang ditawarkan oleh satu pihak kepada pihak lain pada dasarnya tidak berwujud, serta tidak menghasilkan kepemilikan sesuatu. Proses produksinya mungkin dan mungkin juga tidak dikaitkan dengan suatu produk fisik (Kotler dan Amstrong, 1994:39).

Salah satu jasa perbankan yang memberikan banyak kemudahan dalam melakukan berbagai transaksi perbankan adalah pemberian kartu kredit (Kasmir, 2010). Kartu kredit adalah alat pembayaran pengganti uang tunai, berbentuk kartu yang memberikan fasilitas kredit kepada pemiliknya, di mana saat jatuh tempo dapat dibayar dengan jumlah minimum dan sisanya dijadikan kredit. Saat ini dengan semakin banyaknya pasar swalayan dan juga toko-toko kecil yang mulai menerima kartu kredit sebagai alternatif alat pembayaran dibandingkan uang tunai disertai fleksibilitas yang tinggi dan dengan fitur-fiturnya yang semakin beragam serta berkembang menjadikan pertumbuhan bisnis kartu kredit menjadi pesat.

Tercatat dari data Bank Indonesia (BI), jumlah kartu kredit per Agustus 2017 mencapai 14.749.024 kartu dengan nilai penggunaan kartu kredit mencapai Rp 18,173 triliun dengan volume 20,16 juta transaksi. Nilai tersebut naik 5,8 persen jika dibandingkan posisi yang sama tahun lalu sebesar Rp 17,174 triliun dengan volume 19,06 juta transaksi (republika.co.id, 2 Jan 2017). Saat ini terdapat sekitar 20 bank penerbit kartu kredit. Dari sebanyak itu, ada sekitar enam bank yang bisa dikatakan sebagai pemain besar dengan pemilik kartu (card holder) diatas 1 juta nasabah. Keenam bank itu adalah Bank Mandiri, Bank Centra Asia (BCA), Citibank, Bank Negara Indonesia (BNI), Bank CIMB Niaga dan Bank Mandiri (infobanknews.com, 31 Januari 2014).

Saat ini persaingan antara bank penerbit kartu kredit semakin tajam dan ketat, bukan hanya antara bank swasta, akan tetapi juga antar bank milik pemerintah, dan antar bank milik swasta dengan bank milik pemerintah. Hal tersebut menjadikan setiap bank berlomba-lomba menawarkan berbagai macam promosi untuk meningkatkan jumlah pengguna kartu kredit. Memang dalam kegiatan pemasarannya, bank harus mampu mengupayakan agar masyarakat tertarik dan memberikan sepenuhnya kepercayaan untuk menggunakan produk-produk yang ditawarkan bank khususnya dalam hal ini kartu kredit. Dimana kartu kredit adalah kartu yang dapat digunakan sebagai alat pembayaran transaksi jual beli barang dan jasa, dimana pelunasan dapat dilakukan secara sekaligus atau secara angsuran.Karena hingga saat ini kartu kredit merupakan produk andalan dalam bisnis perbankan di Indonesia dan diminati oleh setiap nasabah ( Kasmir, 2008).

Tiap-tiap bank saling berlomba dalam menjaring nasabah melalui kartu kredit yang ditawarkan dengan berbagai macam manfaat, kenyamanan, fungsi yang ada pada kartu kredit. Salah satu strategi yang digunakan oleh perbankan untuk mempengaruhi keputusan nasabah dalam memilih kartu kredit adalah dengan menerapkan strategi promosi penjualan/sales promotion. Menurut Philip Kotler dan Keller (2006:534), Promosi penjualan terdiri dari kumpulan insentif yang beragam, sebagian besar jangka pendek, dirancang untuk mendorong pembelian suatu jasa tertentu secara lebih cepat dan atau lebih besar oleh konsumen atau pedagang. Mengingat begitu ketatnya persaingan di bisnis kartu kredit ini, sangat sulit untuk meningkatkan pangsa pasar maupun membuat nasabah/calon nasabah untuk menggunakan kartu kreditnya. Bank Mandiri sebagai salah satu pemain besar dalam penerbitan kartu kredit, telah memiliki 313 jaringan kantor tersebar di seluruh Indonesia, dengan berbagai produk unggulan seperti : Mandiri first, Trans studio past, Mandiri pass, Mandiri cash dan kartu kredit bank Mandiri (www.bankMandiri.com).Saat ini salah satu cara yang dilakukan Bank Mandiri untuk mempromosikan kartu kredit yakni dengan pemberian program diskon dan hadiah yang dirancang untuk mendorong para nasabah untuk segera melakukan pembelian dan membayar menggunakan kartu kredit. Sehingga hal tersebut diharapkan dapat meningkatkan jumlah transaksi dan memberikan manfaat yang optimal bagi perusahaan.

Keberhasilan perusahaan dalam memproduksi barang maupun jasa, kinerjanya dapat diukur melalui volume dan pertumbuhan penjualan. Begitu juga dengan keberhasilan dari program sales promotion dalam kaitan pemasaran kartu kredit, dapat dibuktikan dengan pertumbuhan penjualan kartu kredit. Tercatat secara nasional di th 2017 , penjualan kartu kredit Bank Mandiri mencapai 1.750 .000 kartu dengan sales volume telah mencapai Rp 1,8 triliun per bulan, dengan outstanding pemakaian Rp 4,3 triliun. Pencapaian tersebut menjadikan Bank Mandiri di tahun 2017 sebagai Bank penerbit kartu kredit Visa terbesar atau nomor 1 di Indonesia (Pride/Edisi Oktober 2017 No 37/2017 pada Agustus 2017).

Peningkatan jumlah peMandiring kartu kredit Mandiri Visa secara nasional dan tercatatnya Bank Mandiri sebagai bank penerbit kartu kredit Visa terbesar di Indonesia, tidak disertai dengan peningkatan jumlah peMandiring kartu kredit Mandiri Visa pada Bank Mandiri cabang Mataram. Bank Mandiri sebagai cabang yang ke-102, mencatat jumlah Mandiri kartu kredit selama tahun 2017 sebagai berikut : 
Tabel 1. Jumlah peMandiring kartu kredit Mandiri Visa Cabang Mataram Periode Januari - Desember 2017

\begin{tabular}{|c|c|}
\hline Periode (bulan) & Jumlah PeMandiring kartu kredit (orang) \\
\hline Jan-13 & 401 \\
\hline Feb-13 & 400 \\
\hline Mar-13 & 359 \\
\hline Apr-13 & 340 \\
\hline May-13 & 360 \\
\hline Jun-13 & 359 \\
\hline Jul-13 & 362 \\
\hline Aug-13 & 370 \\
\hline Sep-13 & 371 \\
\hline Oct-13 & 365 \\
\hline Nov-13 & 370 \\
\hline Dec-13 & 375 \\
\hline
\end{tabular}

Sumber : Card Center PT Bank Mandiri cabang Mataram, Tbk (2017)

Dari data di atas, jumlah peMandiring Mandiri Visa pada Bank Mandiri cabang Mataram tidak mengalami peningkatan, malah terjadi penurunan. Dalam kaitannya dengan hal tersebut, Bank Mandiri secara nasional melakukan berbagai macam promo untuk terus meningkatkan jumlah pengguna kartu kredit antara lain dengan:

1. Pemberian diskon $10 \%-25 \%$ : promo yang memungkinkan pengguna kartu kredit Bank Mandiri Tbk bisa mendapatkan diskon setelah melakukan pembelian pada merchant-merchant.

2. Program cicilan : promo yang memberikan kemudahan bagi pengguna kartu kredit untuk melakukan cicilan terhadap pembelian barang pada merchant-merchant dengan bunga $0 \%$.

3. Program pemberian pinjaman tunai : promo yang memberikan kemudahan dalam pemberian pinjaman uang tunai/cash dengan cara mencicil dalam jangka waktu 3-12 bulan dengan bunga yang kompetitif (0\% $-1.2 \%)$.

4. Reward promo/MANDIRI Point Rewards : promo yang diberikan kepada penguna kartu kredit bank Mandiri dengan menukarkan poin kartu kredit yang terkumpul untuk ditukarkan dengan hadiah/sejumlah barang sesuai katalog.

5. Lounge card promo : khusus untuk grade pengguna kartu kredit bank Mandiri infinite \& Mandiri First yang dapat menikmati fasilitas lounge di sejumlah bandar udara/airport.

Tidak terkecuali untuk Bank Mandiri cabang Mataram, promo kartu kredit yang gencar dilakukan saat ini adalah pemberian diskon dan penukaran point rewards/Mandiri Point rewards. Diskon diberikan bagi para peMandiring kartu kedit yang melakukan transaksi di merchant dengan besaran diskon yang diberikan berkisar antara 10\%-25\%.. Merchant adalah toko-toko yang memiliki kerjasama dengan pihak bank penerbit kartu kredit/Acquirer dimana untuk merchant bank Mandiri cabang Mataram antara lain : Restauran (Delicio, XO SUKI \& CUISINE, de'Bakoel Nasi, Redwood, Naga Restaurant), toko Handphone (Oke Shop), Hotel ( Hotel Lombok Raya, Hotel Grand Legi Mataram), rumah bersalin Permata Hati dan salon Permata. Sedangkan untuk hadiah yang diberikan, terkait dengan pengumpulan point oleh para peMandiring kartu kredit untuk ditukarkan dengan berbagai hadiah eksklusif. Point rewards diperoleh apabila para peMandiring kartu melakukan transaksi belanja menggunakan kartu kredit Mandiri Visa, yg secara otomatis akan mendapatkan Mandiri Point ( $\operatorname{Rp} 25.000,=1$ poin, berlaku kelipatan).

\section{Tujuan Penelitian}

Penelitian ini memiliki tujuan untuk mengetahui signifikansi pengaruh secara parsial dan simultan dari pemberian diskon dan hadiah terhadap penggunaan kartu kredit Bank Mandiri pada peMandiring kartu kredit cabang Mataram, dan untuk mengetahui manakah dari variabel diskon dan hadiah yang memiliki pengaruh dominan terhadap penggunaan. 


\section{METODE PENELITIAN}

\section{Jenis Penelitian}

Jenis penelitian ini menggunakan metode penelitian asosiatif. Penelitian asosiatif merupakan penelitian yang bertujuan untuk mengetahui hubungan antara dua variabel atau lebih. Penelitian asosiatif mempunyai tingkatan yang tertinggi bila dibandingkan dengan penelitian deskriptif dan komparatif. Dengan penelitian asosiatif ini maka akan dapat dibangun suatu teori yang dapat berfungsi untuk menjelaskan, meramalkan dan mengontrol suatu gejala (Sugiyono, 2001:11).

\section{Populasi dan Sampel Penelitian}

Menurut data internal bank Mandiri cabang Mataram bagian kartu kredit, jumlah pengguna kartu kredit pada bulan Desember 2017 adalah sebanyak 375 orang. Dari jumlah tersebut tidak diketahui identitas serta aktivitas penggunaan kartu kreditnya. Dengan pertimbangan tersebut, penentuan jumlah responden menurut Maholtra (1993:62) bahwa jumlah responden paling sedikit 4 atau 5 dikalikan dengan jumlah indikator yang digunakan dalam penelitian. Jadi jumlah responden yang diperlukan dalam penelitian ini adalah minimal $5 \times$ indikator. Dalam penelitian ini terdapat 8 indikator sehingga $5 \times 8$ indikator $=40$ orang dan menurut Winarno Surakhmad (1998: 100) " bahwa untuk jaminan ada baiknya sampel selalu ditambah sedikit lagi dari jumlah matematik tadi “, sehingga sampel yang diambil menjadi 60 orang. Sedangkan teknik pengambilan sampel yang digunakan dalam penelitian ini bersifat accidental sampling. Menurut Santoso dan Tjiptono (2001 : 89-90) Accidental sampling adalah prosedure sampling yang memilih sampel dari orang atau unit yang paling mudah dijumpai atau diakses. Sedangkan menurut Sugiyono (2011:77) Accidental sampling adalah mengambil responden sebagai sampel berdasarkan kebetulan, yaitu siapa saja yang secara kebetulan bertemu dengan peneliti dapat digunakan sebagai sampel bila orang yang kebetulan ditemui cocok sebagai sumber data dengan kriteria utamanya adalah orang tersebut merupakan konsumen atau pembeli yang kebetulan berbelanja di merchant Bank Mandiri menggunakan kartu kredit Bank Mandiri.

\section{Jenis Data}

Jenis data yang digunakan dalam penelitian ini bersumber dari :

\section{Data primer}

Data primer yaitu data secara langsung dari sumber datanya. melalui observasi, wawancara dan penyebaran kuesioner.

2. Data sekunder yaitu data berumber dari dari literatur, jurnal, dan internet, yaitu berupa kajian teori serta penelitian terdahulu.

Data dianalisis menggunakan Analisa statistik deskriptif, dengan banuan program SPSS (Statistical Package for Social Sciences) version 17.0,

\section{HASIL DAN PEMBAHASAN}

\section{Daya Tarik Diskon (X1)}

Rata-rata tanggapan responden untuk variabel diskon dengan indikator daya tarik diskon adalah sebagai berikut :

Tabel 2. Responden untuk Indikator Daya Tarik Diskon

\begin{tabular}{|c|c|c|c|c|c|c|c|}
\hline \multirow{3}{*}{ No } & \multirow{3}{*}{ Daya tarik diskon } & \multicolumn{4}{|c|}{ PeMandiring Kartu Kredit } & \multirow{2}{*}{\multicolumn{2}{|c|}{ TOTAL }} \\
\hline & & \multicolumn{2}{|c|}{ Silver } & \multicolumn{2}{|c|}{ Gold } & & \\
\hline & & $\mathrm{Jlh}$ & $\%$ & $\mathrm{Jlh}$ & $\%$ & jlh & $\%$ \\
\hline 1 & Sangat Menarik ( 5 ) & 2 & 3.33 & 1 & 1.67 & 3 & 5 \\
\hline 2 & Menarik (4) & 21 & 35 & 22 & 36.67 & 43 & 72 \\
\hline 3 & Biasa saja (3) & 6 & 10 & 7 & 11.67 & 13 & 22 \\
\hline 4 & Tidak Menarik (2) & 1 & 1.667 & - & - & 1 & 1.67 \\
\hline 5 & Sangat tidak Menarik (1) & - & - & - & - & - & - \\
\hline
\end{tabular}

Sumber : data primer diolah 
Dari tabel di atas, dapat dijelaskan bahwa dari total 60 orang responden, prosentase responden terbesar memberikan respon positif terhadap daya tarik diskon kartu kredit Bank Mandiri. Dalam hal ini sebagian besar responden setuju bahwa diskon yang diberikan oleh kartu kredit Bank Mandiri memang memiliki daya tarik tersendiri bagi para responden untuk berbelanja menggunakan kartu kreditnya di merchant. Besarnya prosentase responden baik peMandiring kartu kredit gold maupun silver dalam memberikan respon menarik pada daya tarik diskon yang diberikan oleh kartu kredit Bank Mandiri hampir sama banyak.

Terdapat pula respon yang lebih positif dari kedua peMandiring kartu kredit, yang memberikan respon sangat setuju bahwa promo diskon yang diberikan oleh kartu kredit Bank Mandiri memang sangat menarik. Respon ini diperoleh dari peMandiring kartu kredit yang memang sering berbelanja di merchant. Walaupun jumlah prosentase untuk kategori responden yang memberikan respon sangat menarik tidak sebesar prosentase responden yang memberikan tanggapan menarik.

Selanjutnya beberapa responden ada yang lebih memilih memberikan respon biasa saja terhadap daya tarik diskon yang diberikan oleh kartu kredit Bank Mandiri. Besarnya prosentase peMandiring kartu gold dan kartu silver dalam memberikan respon ini, hampir sama besar. Respon tersebut muncul karena para peMandiring kartu kredit khususnya peMandiring kartu gold dalam menggunakan kartu kreditnya, terkadang lebih melihat kepada kebutuhan akan barang yang hendak dibeli tanpa memperhatikan promo diskon yang sedang berlangsung. Selain itu berdasarkan hasil wawancara dengan responden, tidak jarang adanya promo diskon diketahui oleh responden, pada saat responden melakukan transaksi di merchant tersebut. Terdapat satu orang responden dari peMandiring kartu gold yang memberikan respon tidak menarik terhadap daya tarik diskon kartu kredit Bank Mandiri.

\section{Uji Validitas dan Reliabilitas.}

\section{Uji Validitas}

Uji validitas digunakan untuk mengetahui valid atau tidaknya suatu kuesioner. Kesimpulan dapat ditarik dengan membandingkan nilai $r$. Apabila nilai $r_{\text {hitung }}$ lebih besar dari nilai $r_{\text {kritis }}\left(r_{\text {hitung }} \geq 0,30\right)$ maka instrumen penelitian dikatakan valid dan jika sebaliknya dinyatakan tidak valid.

Tabel 3. Nilai $r$ hitung

\begin{tabular}{|c|c|c|}
\hline No & Variabel & Nilai $\mathrm{r}_{\text {hitung }}$ \\
\hline 1. & $\mathrm{X} 1.1$ & 0,463 \\
\hline 2. & $\mathrm{X} 1.2$ & 0,663 \\
\hline 3. & $\mathrm{X} 1.3$ & 0,575 \\
\hline 4. & $\mathrm{X} 2.1$ & 0,319 \\
\hline 5. & $\mathrm{X} 2.2$ & 0,829 \\
\hline 6. & $\mathrm{X} 2.3$ & 0,618 \\
\hline 7. & $\mathrm{Y} 1$ & 0,358 \\
\hline 8. & $\mathrm{Y} 2$ & 0,815 \\
\hline
\end{tabular}

Sumber : Tabel Item-total statistisc (Lampiran )

Dari tabel di atas terlihat bahwa nilai $r$ dari semua variabelnya lebih besar dari nilai $r_{\text {kritis }}$ yaitu 0,30 sehingga dapat ditarik kesimpulan bahwa instrumen penelitian dinyatakan valid.

\section{Uji Reabilitas}

Selanjutnya untuk melakukan uji reabilitas menggunakan pendekatan cronbach alpha ( $\alpha$ ). Suatu konstruk atau variabel dikatakan reliable apabila memberikan nilai cronbach alpha $(\alpha)>$ (lebih besar dari) 0,6

Tabel 4. Nilai Cronbach Alpha

\begin{tabular}{|c|c|}
\hline $\mathrm{N}$ of item & Cronbach Alpha \\
\hline 8 & 0,838 \\
\hline
\end{tabular}

Sumber : Tabel reliability statistics (Lampiran ) 
Dari Tabel 4 di atas, dapat dilihat bahwa nilai Cronbach Alpha $>0,6$ yaitu $0,838>0,6$ sehingga dapat dikatakan bahwa pertanyaan seluruh variabel dalam keadan reliable.

\section{Uji Asumsi Klasik}

\section{Uji Normalitas}

Hasil uji normalitas data dapat dilihat melalui analisa grafik berikut ini :

Grafik 1

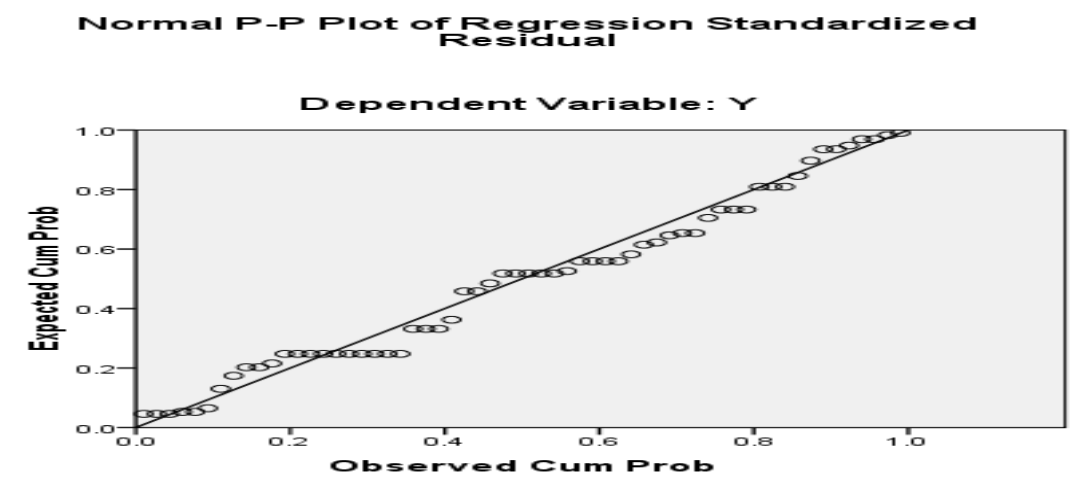

Grafik normal plot menunjukkan titik-titik menyebar disekitar garis diagonal serta penyebarannya mengikuti arah garis diagonal, hal ini berarti data berdistribusi normal. Atau dapat juga dilihat pada grafik histogram berikut ini :

Grafik 2

Histogram

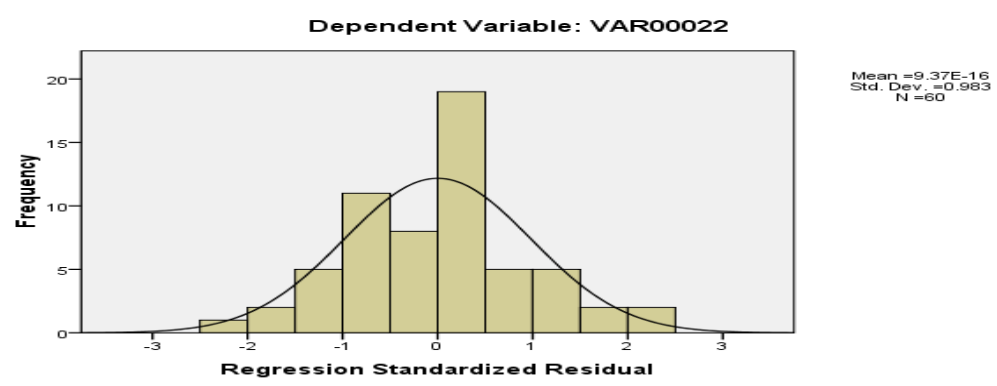

Grafik histogram diatas menunjukkan pola distribusinya tidak menceng (skewness) ke kiri atau ke kanan, maka model regresi memenuhi asumsi normalitas.

\section{Uji Multikolinieritas}

Untuk mendeteksi gejala multikolinieritas dilakukan dengan cara melihat nilai Variance Inflation Factor (VIF) dan tolerance pada tabel berikut :

Tabel 5. Variance Inflation Factor (VIF)

\begin{tabular}{|c|c|c|c|}
\hline \multirow{2}{*}{ No } & \multirow{2}{*}{ Variabel } & \multicolumn{2}{|c|}{ Collinearity Statistics } \\
\cline { 3 - 4 } & & Tolerance & VIF \\
\hline \multirow{2}{*}{1} & Diskon (X1) & 0,537 & 1,861 \\
\hline 2 & Hadiah (X2) & 0,537 & 1,861 \\
\hline
\end{tabular}

Sumber : Tabel Coefficients ${ }^{\mathrm{a}}$ (lampiran ) 
Pada hasil perhitungan diatas terlihat pada tabel 4.17 tidak ada satupun variabel independent yang memiliki VIF lebih dari 10 (VIF <10) dan nilai Tolerance $>0,10$ jadi dapat disimpulkan bahwa tidak ada multikolinieritas antar variabel.

\section{Uji Heteroskedastisitas}

Untuk mengetahui ada tidaknya gejala heteroskedastisitas dapat dilakukan dengan melihat pola diagram pencar berikut :

Grafik 3 .

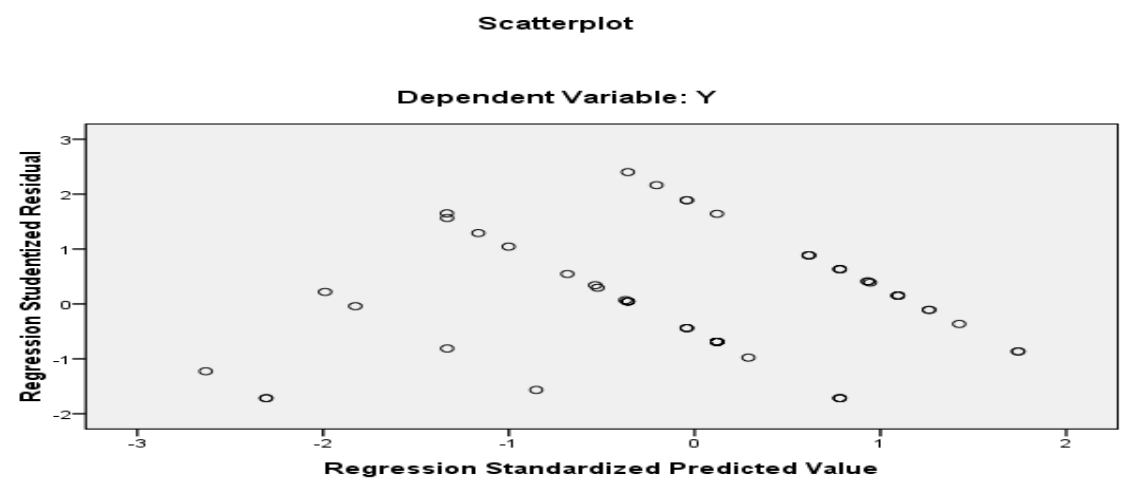

Diagram pencar tidak membentuk pola atau acak, maka dapat ditarik kesimpulan regresi tidak mengalami gangguan heterokedastisitas.

\section{Uji Autokorelasi}

Autokorelasi diuji dengan Uji Durbin-Watson (D-W test). Jika dU $<$ DW $<4$-dU maka tidak terjadi autokorelasi. Hasil uji dapat dilihat pada tabel berikut :

Tabel 6. Nilai Durbin Watson

\begin{tabular}{|c|c|}
\hline Model & Durbin-Watson \\
\hline 1 & 2,037 \\
\hline
\end{tabular}

Sumber : Tabel Model Summary ${ }^{\mathrm{b}}$ (Lampiran )

Dari tabel di atas, terlihat nilai Durbin-Watson $=2,037$. DW tabel dengan menggunakan nilai signifikansi 0,05 dengan jumlah sampel $n=60$ dan jumlah variabel independen $=2(k=2)$. maka dalam tabel Durbin Watson akan didapat nilai

$\mathrm{dU}=1,6518$.

Diketahui 4-dU $=4-1,6518=2,3482$

Karena 1,6518 <2,037 <2,3482 maka dapat disimpulkan tidak terjadi autokorelasi.

\section{Analisis Regresi Berganda}

Analisis regresi linier berganda digunakan untuk mengetahui besarnya perubahan variabel penggunaan kartu kredit yang disebabkan oleh perubahan yang terjadi pada variabel Diskon (X1) dan Hadiah (X2). Hasil pengolahan melalui SPSS diperoleh hasil seperti pada tabel berikut :

Tabel 7. Nilai Koefisien Regresi

\begin{tabular}{|c|c|}
\hline Variabel & Koefisien Regresi \\
\hline Konstanta & 1,018 \\
\hline $\mathrm{X} 1$ & 0,478 \\
\hline $\mathrm{X} 2$ & 0,162 \\
\hline
\end{tabular}

Sumber: Tabel Coefficients ${ }^{\mathrm{a}}$ (lampiran ) 
Persamaan regresi dirumuskan sebagai berikut:

$\mathrm{Y}=\mathrm{a}+\mathrm{b} 1 \mathrm{X} 1+\mathrm{b} 2 \mathrm{X} 2$ Sehingga berdasarkan tabel di atas maka persamaan regresinya adalah :

Penggunaan Kartu Kredit = 1,018 + 0,478 Diskon + 0,162 Hadiah

Dari persamaan tersebut berarti bahwa

1. Konstanta sebesar 1,018 dapat diartikan jika variabel diskon (X1) dan Hadiah (X2) adalah sama dengan nol, maka penggunaan kartu kredit (Y) sebesar 1,018.

2. Koefisien regresi b1 $=0,478$ artinya apabila variabel diskon (X1) meningkat sebesar satu satuan maka penggunaan kartu kredit (Y) akan meningkat sebesar 0,478 dengan asumsi hadiah (X2) terhadap penggunaan kartu kredit (Y) dianggap konstan.

3. Koefisien regresi b2 $=0,162$ artinya apabila hadiah $(\mathrm{X} 2)$ meningkat sebesar satu satuan maka penggunaan kartu kredit (Y) akan meningkat 0,162 dengan asumsi variabel diskon (X1) terhadap penggunaan kartu kredit (Y) dianggap konstan.

\section{Koefisien Determinasi (R Square)}

Koefisien determinasi $\left(\mathrm{R}^{2}\right)$ pada intinya mengukur seberapa besar kemampuan model dalam menerangkan variabel dependen (terikat).

Tabel. 8.Nilai Koefisien Determinasi

\begin{tabular}{|c|c|}
\hline Model & Koefisien determinasi \\
\hline 1 & 0,704 \\
\hline
\end{tabular}

Sumber : Tabel Model Summary b (Lampiran 4)

Besarnya nilai Adjusted $R$ Square pada tabel Model summary di atas adalah 0,704. Hal ini berarti 70,4\% penggunaan kartu kredit dipengaruhi oleh variasi dari kedua variabel independen, yaitu diskon (X1) dan Hadiah (X2). Sedangkan sisanya sebesar 29,6\% dipengaruhi oleh variabel-variabel yang lain diluar penelitian ini. Dan karena $\mathrm{R}^{2}$ nilainya mendekati satu, maka dapat dikatakan bahwa pengaruh variabel bebas (diskon dan hadiah) adalah kuat terhadap variabel terikat (penggunaan kartu kredit).

\section{Uji Simultan (F Test)}

Hasil analisis diperoleh nilai $\mathrm{F}$ sebesar 67,735 dengan probabilitas 0,00 . Karena nilai probabilitas $<0,05$ $(0,00<0,05)$, atau dengan $\mathrm{F}$ Tabel $5 \%(\mathrm{n}-1)=4,00$, maka Ho ditolak dan Ha diterima, yang artinya secara simultan variabel diskon dan hadiah berpengaruh signifikan terhadap penggunaan kartu kredit.

\section{Uji Parsial (T Test)}

Uji parsial untuk mengetahui variabel mana yang paling dominan mempengaruhi

Tabel 9. Nilai Koefisien Regresi

\begin{tabular}{|c|c|}
\hline Variabel & $\mathrm{T}$ \\
\hline Diskon & 6,914 \\
\hline Hadiah & 2,162 \\
\hline
\end{tabular}

Dari uji parsial, yang dominan mempengaruhi penggunaan kartu kredit adalah diskon, karena $\mathrm{T}$ tes $(6,914)>\mathrm{T}$ table $(1,96)$ 


\section{SIMPULAN DAN SARAN}

\section{Simpulan}

Berdasarkan hasil analisis data dan pembahasan yang telah diuraikan sebelumnya, maka dapat dikemukakan beberapa kesimpulan sebagai berikut :

1. Secara parsial pemberian diskon dan dan hadiah berpengaruh signifikan terhadap penggunaan kartu kredit Bank Mandiri di Kota Mataram. Hal ini dibuktikan dengan nilai probabilitas masing masing variabel yang lebih kecil dari 0,05 .

2. Secara simultan pemberian diskon dan hadiah berpengaruh signifikan terhadap penggunaan kartu kredit Bank Mandiri di Kota Mataram. Hal ini dibuktikan dengan probabilitas nilai f yang lebih kecil dari 0,05.

\section{Saran-saran}

Berasarkan atas hasil penelitian, maka dapat disarankan bahwa ;

1, Dalam penelitian ini hanya melihat penggunaan kartu kredit Bank Mandiri berdasarkan pemberian diskon dan hadiah, untuk penelitian selanjutnya sebaiknya ditambah dengan faktor-faktor lain yang bisa memberikan gambaran lebih lengkap tentang penggunaan kartu kredit.

2. Penelitian ini merupakan penelitian yang bersifat Kuantitatif, sebaiknya untuk penelitian selanjutnya dilakukan penelitian sejenis yang bersifat Kualitatif untuk memperoleh gambaran yang lebih kaya dan mendalam mengenai tanggapan nasabah terhadap kartu kredit.

3. Bagi Bank Mandiri cabang Mataram, penelitian ini membuktikan bahwa pemberian diskon dan hadiah memberikan pengaruh positif terhadap penggunaan kartu kredit Bank Mandiri, sehingga untuk promosi selanjutnya diharapkan terus mengembangkan pemberian diskon dan hadiah yang lebih variatif lagi, terutama dalam hal promo pemberian diskon terutama frekuensi dan besaran diskon yang diberikan , karena dalam penelitian ini terbukti bahwa variabel diskon merupakan variabel yang paling dominan berpengaruh terhadap penggunaan kartu kredit Bank Mandiri di Kota Mataram.

4. Selain pemberian diskon, kerjasama antara Bank Mandiri dengan merchant-merchant terutama toko-toko, supermarket-supermarket, travel-travel tiket, hotel-hotel terutama yang berada di Mataram diperbanyak lagi karena hal tersebut menjadi salah satu point penting bagi para peMandiring kartu kredit untuk aktif menggunakan kartu kreditnya.

5. Bagi manajemen Bank Mandiri Cabang Mataram sebaiknya tetap intensif melakukan kegiatan promosi secara terprogram baik melalui media cetak, elektronik maupun kegiatan promosi lainnya.

6. Bukan hanya besaran diskon, variasi hadiah yang menjadi perhatian responden dalam penggunaan kartu kredit bank Mandiri yang dimiliki namun pencetakan rekening secara administratif yang tepat waktu menjadi hal yang harus diperhatikan bagi pihak manajemen bank Mandiri juga

\section{DAFTAR PUSTAKA}

Kasmir, 2008. Bank dan Lembaga Keuangan lainnya.Edisi Revisi. Raja Graffindo edition, New Jersey : Prentice Hall International Inc.

Kasmir,2010. Bank dan Lembaga Keuangan Lainnya. Raja Graffindo

Kotler, Philip \& Armstrong, Gary ,1994 . Manajemen Pemasaran, edisi Keenam. Erlangga Jakarta

Kotler, Philip and Keller, Kevin Lane, 2006, Marketing Management, (12 th ed.), New Jersey : Pearson Education, Inc.

Maholtra K.Naresh.1993. Marketing Research An Applied Orientation, second Pers. Jakarta.

Sugiyono, 2001. Metode Penelitian Bisnis, Cetakan Kesembilan, Alfabeta Bandung

Sugiyono. 2010. Metode Penelitian Pendidikan. Alfabeta Bandung

Sugiyono. 2011. Metode Penelitian Kualitatif, Kuantitatif, dan RnD. Alfabeta Bandung

Tjiptono, Fandy. (2008).Strategi Pemasaran, Andi offset. Yogyakarta 